\title{
ANALISIS PERBANDINGAN BATERAI LITHIUM-ION, LITHIUM-POLYMER, LEAD ACID DAN NICKEL-METAL HYDRIDE PADA PENGGUNAAN MOBIL LISTRIK - REVIEW
}

\author{
Muhammad Thowil Afif, Ilham Ayu Putri Pratiwi \\ Jurusan Teknik Mesin Fakultas Teknik Universitas Brawijaya Malang \\ Jalan MT Haryono 167 Lowokwaru \\ (0341) 587711 \\ E-mail: ayu15.putri@gmail.com
}

\begin{abstract}
A battery is an important part of electric vehicle which is converting the chemical energy into electrical energy. There are two types of battery based on the occurrence i.e. primary and secondary batteries. In the market there are a lot of secondary battery types for electric vehicle i.e. Lithium-ion, Lithium Polymer, Lead acid, and Nickel Metalh Hydrarde batteries. Because of that, a study comparation of secondary battery types was needed. Meta-analysis method was used to analyze the comparison between secondary battery types. The results showed that each battery have different spesifications, advantages, and disadvantages. There are a lot of consideration to choose battery for electric vehicle including initial cost, life time, mass, volume, temperature sensitivity, acces to care and acces to product.
\end{abstract}

Keywords: Lithium-Ion Batteries, Lithium-Polymer Batteries, Lead Acid Batteries, Nickel-Metal Hydrade Batteries

\section{PENDAHULUAN}

Kendaraan listrik pasti memerlukan baterai sebagai sumber tenaga penggerak kompone-komponen listrik, seperti: motor starter, penerangan (lampu), klakson, dan lain sebagainya. Baterai sangat penting sebagai pemasok energi ke seluruh komponen kelistrikan yang ada pada kendaraan listrik, hal ini menjdikan baterai sangat vital sebagai sumber tenaga kompone-komponen listrik. Baterai ditemukan oleh ahli fisika dari Perancis bernama Gaston Plante pada tahun 1859.

Baterai atau akkumulator adalah sebuah sel listrik dimana didalamnya berlangsung proses elektrokimia yang reversible (dapat berkebalikan) dengan efisiensinya yang tinggi. Yang dimaksud dengan reaksi elektrokimia reversibel adalah didalam baterai dapat berlangsung proses pengubahan kimia menjadi tenaga listrik (proses pengosongan) dan sebaliknya dari tenaga listrik menjadi tenaga kimia (proses pengisian) dengan cara proses regenerasi dari elektroda - elektroda yang dipakai yaitu, dengan melewatkan arus listrik dalam arah polaritas yang berlawanan didalam sel. Baterai menghasilkan listrik melalui proses kimia [1]. Terdapat 2 jenis baterai berdasakan pada proses yang terjadi, yaitu:

\section{Primary battery}

Baterai yang hanya dapat digunakan sekali saja dan dibuang. Material elektrodanya tidak dapat berkebalikan arah ketika dilepaskan.

\section{Secondary battery}

Baterai yang dapat digunakan dan diisi ulang beberapa kali, proses kimia yang terjadi di dalam baterai ada reversibel, dan baha aktif dapat kembali ke kondisi semula dengan pengisian sel.

Baterai sekunder sendiri terdapat banyak jenisnya di pasaran, antara lain:

a) Baterai ion litium (Li-ion atau LIB)

Di dalam baterai ini, ion litium bergerak dari elektroda negatif ke elektroda positif saat dilepaskan, dan kembali saat diisi ulang. Baterai Li-ion memakai senyawa litium interkalasi sebagai bahan elektrodanya, berbeda dengan litium metalik yang dipakai di baterai litium non-isi ulang. Baterai ion litium umumnya dijumpai pada barangbarang elektronik konsumen. Baterai ini merupakan jenis baterai isi ulang 
yang paling populer untuk peralatan elektronik portabel, karena memiliki salah satu kepadatan energi terbaik, tanpa efek memori, dan mengalami kehilangan isi yang lambat saat tidak digunakan. Selain digunakan pada peralatan elektronik konsumen, LIB juga sering digunakan oleh industri militer, kendaraan listrik, dan dirgantara. Sejumlah penelitian berusaha memperbaiki teknologi LIB tradisional, berfokus pada kepadatan energi, daya tahan, biaya, dan keselamatan intrinsik.

b) Baterai Lithium Polymer (Li-Po) Hampir sama dengan baterai Li- Ion akan tetapi baterai Li-Po tidak menggunakan cairan sebagai elektrolit melainkan menggunakan elektrolit polimer kering yang berbentuk seperti lapisan plastik film tipis. Lapisan film ini disusun berlapis-lapis diantara anoda dan katoda yang mengakibatkan pertukaran ion. Dengan metode ini baterai LiPo dapat dibuat dalam berbagai bentuk dan ukuran. Diluar dari kelebihan arsitektur baterai LiPo, terdapat juga kekurangan yaitu lemahnya aliran pertukaran ion yang terjadi melalui elektrolit polimer kering. Hal ini menyebabkan penurunan pada charging dan discharging rate. Masalah ini sebenarnya bisa diatasi dengan memanaskan baterai sehingga menyebabkan pertukaran ion menjadi lebih cepat, namun metode ini dianggap tidak dapat untuk diaplikasikan pada keadaan seharihari. Seandainya para ilmuwan dapat memecahkan masalah ini maka risiko keamanan pada batera jenis lithium akan sangat berkurang.

c) Baterai Lead Acid (Accu)

Baterai Lead Acid atau biasa disebut aki merupakan salah satu jenis baterai yang menggunakan asam timbal (lead acid) sebagai bahan kimianya. Secara umum terdapat dua jenis baterai leadacid, yaitu : (a). Starting Battery, dan (b). Deep Cycle Battery.

d) Baterai Nickel-Metal Hydride (Ni-MH) Baterai jenis ini dibuat engan komponen yang lebih terjangkau dan ramah lingkungan. Baterai $\mathrm{Ni}-\mathrm{MH}$ menggunakan ion hidrogen untuk menyimpan energi, tidak seperti baterai lithium ion yang menggunakan ion lithium. Baterai $\mathrm{Ni}-\mathrm{MH}$ terdiri dari campuran nikel dan logam lain seperti titanium. Baterai ini biasanya mengandung pula komponen logam lain seperti mangan, aluminium, kobalt, zirconium, dan vanadium. Logamlogam tersebut pada umunya berfungsi sebagai penangkap ion hidrogen yang dilepaskan untuk memastikan tidak mencapi fase gas.

Banyaknya jenis baterai sekunder yang ada dipasaran maka diperlukan kajian untuk mendapatkan jenis baterai terbaik dan sesuai dengan kebutuhan untuk mobil listrik. Menurut Albright, (2012) dalam penelitiannya mengenai perbandingan antara Lead Acid dan Lithium-Ion dalam aplikasi penyimpanan stasionari menyebutkan bahwa pada saat ini baterai Lithium-Ion merupakan baterai yang lebih baik untuk digunakan dalam berbagai situasi, khususnya pada iklim panas, meskipun memiliki biaya awal yang lebih tinggi. Selain itu, baterai Lithium-Ion memiliki efisiensi yang lebih tinggi bila dibandingkan dengan baterai Lead Acid.

Menurut Fendy, (2012) dalam penelitiannya tentang karakteristik Baterai Lithium-Polymer menyebutkan bahwa bateri jenis Lithium-Polymer memiliki standar yang lebih baik bila dibandingkan dengan baterai $\mathrm{NiMH}$ sepeti memiliki massa yang lebih ringan dan tersedia dalam berbagai macam bentuk, memiliki kapasitas penyimpanan energi listrik yang besar, serta memiliki tingkat discharge rate energi yang tinggi [2]

Menurut Suppo, (2014) dalam jurnalnya mengenai perbandingan antara baterai LithiumIon dengan Baterai Nickel-Metal Hydrade menjelaskan bahwa baterai Li-on merupakan pilihan terbaik apabila dilihat dari segi massa baterai karena memiliki massa yang ringan. Sedangkan apabila dilihat dari segi keamanan dan ekonomi baterai Ni-MH merupakan pilihan yang terbaik [3].

Berdasarkan uraian di atas baterai merupakan sebuah perangkat yang vital bagi kendaraan listrik, dan terdapat berbagai jenis baterai yang ada dipasaran terutama pada baterai sekunder. Sehingga penulis akan mereview perbandingan antara baterai LithiumIon, baterai Lithium-Polymer, baterai Lead- 
Acid, dan baterai Nickel-Metal Hydride pada penggunaannya dalam kendaraan listrik.

\section{METODOLOGI PENELITIAN}

Dalam penelitian ini menggunakan metode meta-analisis yaitu metode survey yang dilakukan terhadap data-data yang terdapat di dalam beberapa laporan penelitian. Metode ini bertujuan untuk menganalisis perbandingan antara baterai Lithium-Ion, baterai LithiumPolymer, baterai Lead-Acid, dan baterai NickelMetal Hydride pada penggunaannya dalam kendaraan listrik.

Pengumpulan data dari berbagai jurnal di download melalui science direct, proquest, skripsi, tesis, dan disertasi. Berikut ada flowchart dalam metode penelitian yang akan dilakukan:

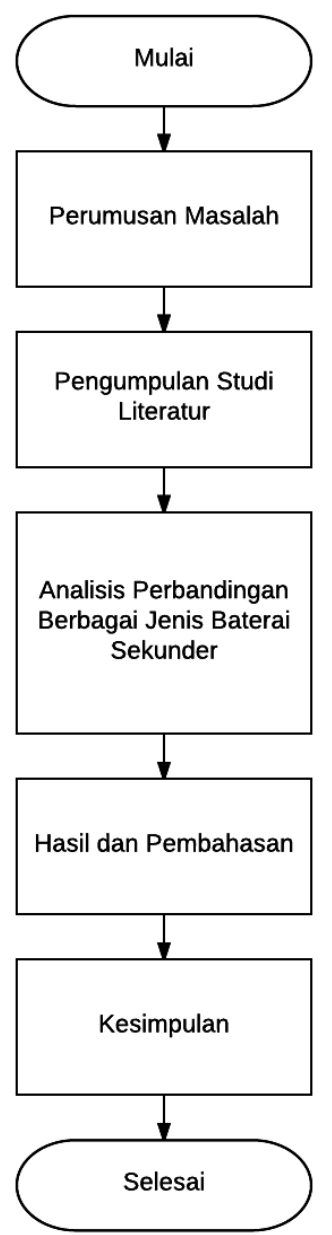

Gambar 1. Flowchart Metode Penelitian

\section{HASIL DAN PEMBAHASAN Hasil}

Analisis pembahasan berupa tabel yang berisi spesifikasi-spesifikasi, kelebihan, dan kekurangan dari masing-masing jenis baterai. Hasil pada penelitian ini dapat dilihat pada Tabel 1-3.

\section{Pembahasan}

Dari hasil di atas, setiap jenis baterai jenis baterai memiliki spesifikasi, kelebihan dan kekurangan masing-masing. Ketika user akan memiliki jenis baterai maka banyak faktor yang harus dipertimbangkan. Pentingnya biaya awal, life time, massa, volume, sensitivitas suhu, akses perawatan dan akses ke produk semua memainkan peran dalam seleksi baterai.

Jika kita bandingkan antara baterai Lithium-ion dengan Lithium-polymer, maka lebih baik menggunakan baterai LithiumPolymer. Karena dengan massa yang lebih ringan, baterai ini bisa menghasilkan energi spesifik yang hampir sama besar dengan baterai Lithium-Ion.

Dan jika membandingkan antara baterai Lead Acid dengan Nickel Metal-Hydrade maka lebih baik menggunakan baterai Ni-MH. Karena baterai ini memiliki massa dua kali lebih ringan dari baterai Lead Acid, dengan massa yang lebih ringan tersebut baterai ini dapat menghasilkan energi spesifik yang lebih tinggi. Selain itu, baterai $\mathrm{NiMH}$ lebih ramah lingkungan, karena baterai lead acid mengandung timbal sehingga menyebabkan baterai ini tidak ramah lingkungan.

\section{KESIMPULAN}

1. Baterai merupakan sebuah sel listrik dimana didalamnya berlangsung proses elektrokimia yang reversible (dapat berkebalikan ) dengan efisiensinya yang tinggi.

2. Baterai terdiri 2 jenis, yaitu : primary batteries dan secondary batteries. Yang banyak digunakan untuk kendaraan listrik adalah secondary batteries.

3. Baterai Lithium-Ion, Lithium-Polymer, Lead Acid, dan Nickel Metal Hydrade masingmasing memiliki spesifikasi, kelebihan, dan kekurangan.

4. Ketika akan memilih jenis baterai maka banyak faktor yang harus dipertimbangkan. Pentingnya biaya awal, life time, massa, volume, sensitivitas suhu, akses perawatan dan akses ke produk semua memainkan peran dalam seleksi baterai. 
Tabel 1. Spesifikasi Baterai Lithium-Ion, Lithium-Polymer, Lead Acid, dan Nickel Metal Hydrade

\begin{tabular}{|c|c|c|c|c|c|}
\hline NO & Spesifikasi & $\begin{array}{l}\text { Lithium-Ion } \\
{[4]}\end{array}$ & $\begin{array}{l}\text { Lithium- } \\
\text { Polymer [5] }\end{array}$ & Lead Acid [6] & $\begin{array}{l}\text { Nickel-Metal } \\
\text { Hydrade [7] }\end{array}$ \\
\hline 1. & Weight (kg) & 2.15 & 2 & 10 & 5.5 \\
\hline 2. & $\begin{array}{l}\text { Specific Energy } \\
(\text { Wh/kg) }\end{array}$ & 150 & 150 & 40 & 65 \\
\hline 3. & $\begin{array}{l}\text { Initial Cost } \\
(\$ / k W h)\end{array}$ & 600 & - & 100 & 100 \\
\hline 4. & $\begin{array}{l}\text { Typical state of } \\
\text { charge window }\end{array}$ & $80 \%$ & - & $50 \%$ & - \\
\hline 5. & $\begin{array}{l}\text { Temperature } \\
\text { sensitivity }\end{array}$ & $>45^{\circ} \mathrm{C}$ & - & $>25^{\circ} \mathrm{C}$ & $>45^{\circ} \mathrm{C}$ \\
\hline 6. & Efficiency & $\begin{array}{c}\text { 100\% @20-hr- } \\
\text { rate } \\
\text { 99\% @4-hr- } \\
\text { rate } \\
\text { 92\% @1-hr- } \\
\text { rate }\end{array}$ & - & $\begin{array}{c}\text { 100\% @20-hr- } \\
\text { rate } \\
\text { 80\% @4-hr- } \\
\text { rate } \\
\text { 60\% @1-hr- } \\
\text { rate }\end{array}$ & - \\
\hline 7. & $\begin{array}{l}\text { Voltage } \\
\text { increments }\end{array}$ & 3.7 & 3.7 & 2 & 1.2 \\
\hline 8. & $\begin{array}{l}\text { Charging } \\
\text { Temperature }\end{array}$ & $0-45$ & - & $0-25$ & $0-45$ \\
\hline 9. & $\begin{array}{l}\text { Deep Cycle Life } \\
\text { (times) }\end{array}$ & 500 & - & - & 500 \\
\hline 10. & $\begin{array}{l}\text { Environmental } \\
\text { friendly or not }\end{array}$ & Yes & Yes & $\begin{array}{l}\text { No (because } \\
P b \text { and Acid) }\end{array}$ & Yes \\
\hline 11. & Charge method & $\begin{array}{c}\text { Constant } \\
\text { current + } \\
\text { constant } \\
\text { voltage }\end{array}$ & $\begin{array}{c}\text { Constant } \\
\text { current + } \\
\text { constant } \\
\text { voltage }\end{array}$ & $\begin{array}{c}\text { Constant } \\
\text { current + } \\
\text { constant } \\
\text { voltage }\end{array}$ & $\begin{array}{c}\text { Constant } \\
\text { current } \\
\text { multiple steps }\end{array}$ \\
\hline
\end{tabular}

Tabel 2. Kelebihan Baterai Lithium-Ion, Lithium-Polymer, Lead Acid, dan Nickel Metal Hydrade

\begin{tabular}{|c|l|l|l|l|}
\hline NO & \multicolumn{1}{|c|}{ Lithium-Ion [4] } & Lithium-Polymer [5] & \multicolumn{1}{|c|}{ Lead Acid [6] } & $\begin{array}{l}\text { Nickel-Metal Hydrade } \\
\text { [7] }\end{array}$ \\
\hline 1. & $\begin{array}{l}\text { Baterai Lithium-Ion } \\
\text { yang ringan } \\
\text { dibandingkan } \\
\text { dengan baterai isi } \\
\text { ulang lain dari berat } \\
\text { yang sama. }\end{array}$ & $\begin{array}{l}\text { Baterai Lithium } \\
\text { Polymer memiliki } \\
\text { massa yang lebih } \\
\text { ringan, dan baterai ini } \\
\text { dapat dibuat dihampir } \\
\text { berbagai ukuran atau } \\
\text { bentuk. }\end{array}$ & $\begin{array}{l}\text { Baterai Lead Acid } \\
\text { adalah salah satu } \\
\text { yang terbaik dalam } \\
\text { hal kehandalan dan } \\
\text { kemampuan bekerja. }\end{array}$ & $\begin{array}{l}\text { Baterai Nickel-Metal } \\
\text { Hydrade memiliki } \\
\text { kapasitas yang cukup } \\
\text { besar, kurang lebih } \\
30 \%-40 \% \text { lebih tinggi. }\end{array}$ \\
\hline 2. & $\begin{array}{l}\text { Memiliki kepadatan } \\
\text { energi yang sangat } \\
\text { tinggi, sehingga } \\
\text { banyak energi dapat } \\
\text { disimpan di } \\
\text { dalamnya. }\end{array}$ & $\begin{array}{l}\text { Baterai Lithium } \\
\text { Polymer menawarkan } \\
\text { kapasitas yang lebih } \\
\text { tinggi, yang } \\
\text { memungkinkan } \\
\text { baterai ini memiliki } \\
\text { daya berlebih. }\end{array}$ & $\begin{array}{l}\text { Mampu untuk } \\
\text { menghadapi kondisi } \\
\text { lambat, cepat dan } \\
\text { perngisian daya } \\
\text { berlebihan. }\end{array}$ & $\begin{array}{l}\text { Baterai Nickel-Metal } \\
\text { Hydrade kurang rentan } \\
\text { terhadap memori, } \\
\text { dapat diremajakan. }\end{array}$ \\
\hline 3. & $\begin{array}{l}\text { Biaya hilang oleh } \\
\text { Baterai Lithium-lon } \\
\text { adalah serendah 5\% } \\
\text { per bulan. }\end{array}$ & $\begin{array}{l}\text { Baterai Lithium } \\
\text { Polymer menawarkan } \\
\text { laju discharge yang } \\
\text { jauh lebih tinggi. }\end{array}$ & $\begin{array}{l}\text { Mampu untuk } \\
\text { bertahan tidak aktif } \\
\text { dalam jangka } \\
\text { panjang tanpa } \\
\text { larutan elektrolit. }\end{array}$ & $\begin{array}{l}\text { Baterai Nickel-Metal } \\
\text { Hydrade ramah } \\
\text { lingkungan, racun yang } \\
\text { dikandung pun ringan } \\
\text { saja. }\end{array}$ \\
\hline
\end{tabular}


Tabel 3. Kekurangan Baterai Lithium-Ion, Lithium-Polymer, Lead Acid, dan Nickel Metal Hydrade

\begin{tabular}{|c|c|c|c|c|}
\hline NO & Lithium-Ion[4] & Lithium-Polymer[5] & Lead Acid[6] & $\begin{array}{c}\text { Nickel-Metal } \\
\text { Hydrade[7] }\end{array}$ \\
\hline 1. & $\begin{array}{l}\text { Baterai Lithium-Ion } \\
\text { memiliki life time } \\
\text { yang pendek dari } 2 \\
\text { sampai } 3 \text { tahun dari } \\
\text { tanggal pembuatan. }\end{array}$ & $\begin{array}{l}\text { Baterai Lithium } \\
\text { Polymer memiliki life } \\
\text { time yang lebih } \\
\text { pendek daripada } \\
\text { baterai NiMH. Mereka } \\
\text { rata-rata hanya 300- } \\
400 \text { siklud jika dirawat } \\
\text { dengan baik. }\end{array}$ & $\begin{array}{l}\text { Pada iklim panas } \\
\text { dimana suhu rata-rata } \\
\text { adalah } 92^{\circ} \mathrm{F} \text {, siklus } \\
\text { hidup Baterai Lead } \\
\text { Acid akan turun } \\
\text { menjadi } 50 \% \text {. }\end{array}$ & $\begin{array}{l}\text { Baterai Nickel-Metal } \\
\text { Hydrade memiliki } \\
\text { limited service life, } \\
\text { deep discharge } \\
\text { mengurangi layanan } \\
\text { hidup. }\end{array}$ \\
\hline 2. & $\begin{array}{l}\text { Baterai Lithium-Ion } \\
\text { mengalami } \\
\text { degradasi lebih cepat } \\
\text { jika mereka terkena } \\
\text { panas dibandingkan } \\
\text { dengan paparan } \\
\text { suhu normal karena } \\
\text { mereka sangat } \\
\text { sensitive terhadap } \\
\text { suhu tinggi. }\end{array}$ & $\begin{array}{l}\text { Sifat sensitif dan kimia } \\
\text { dari baterai dapat } \\
\text { menyebabkan } \\
\text { kebakaran, hendaknya } \\
\text { baterai mendapatkan } \\
\text { punctured dan } \\
\text { melepaskannya ke } \\
\text { udara. }\end{array}$ & $\begin{array}{l}\text { Baterai Lead Acid } \\
\text { meskipun relatif lebih } \\
\text { aman dari baterai lain } \\
\text { tetapi mereka } \\
\text { menyebabkan banyak } \\
\text { kerusakan lingkungan } \\
\text { pada skala pendek. }\end{array}$ & $\begin{array}{l}\text { Baterai Nickel-Metal } \\
\text { Hydrade } \\
\text { membutuhkan } \\
\text { algoritma biaya yang } \\
\text { kompleks. Sensitif } \\
\text { untuk menjual, } \\
\text { karena mahal. }\end{array}$ \\
\hline 3. & $\begin{array}{l}\text { Baterai Lithium-Ion } \\
\text { hancur jika mereka } \\
\text { benar-benar habis. }\end{array}$ & $\begin{array}{l}\text { Baterai Lithium } \\
\text { Polymer } \\
\text { membutuhkan } \\
\text { perawatan khusus } \\
\text { dalam cara mereka } \\
\text { dibebankan, dibuang, } \\
\text { dan disimpan. } \\
\text { Peralatan dapat harga } \\
\text { yang mahal. }\end{array}$ & $\begin{array}{l}\text { Baterai Lead Acid } \\
\text { rentan terhadap } \\
\text { korosi yang sering } \\
\text { terjadi baik karena } \\
\text { elektrolisis atau } \\
\text { overfilling. Korosi } \\
\text { dapat menurunkan } \\
\text { waktu hidup baterai \& } \\
\text { harus dihindari } \\
\text { melalui perawatan } \\
\text { yang tepat. }\end{array}$ & $\begin{array}{l}\text { Baterai Nickel-Metal } \\
\text { Hydrade tidak } \\
\text { menyerap } \\
\text { overcharge dengan } \\
\text { baik, trickle charge } \\
\text { harus tetap rendah. }\end{array}$ \\
\hline
\end{tabular}

DAFTAR PUSTAKA

[1] Chamma, Bukry, 2015, Perancangan Alat Pengisi Baterai Lead Acid Berbasis Mikrokontroler ATMEGA 8535, Medan: Universitas Sumatera Utara.

[2] Christian, Fendy, 2012, Mengenal Baterai Lithium Polymer (LiPo), Jakarta: Universitas Gunadarma.

[3] SUPPO, 2014, NiMH Battery vs Li-On Battery, China: Union Suppo Battery.

[4] Oswal, Mehul, 2010, A comparative Study of Lithium-Ion Batteries, USA: University of Southen California.
[5] Schneider, Brian, 2012, A Guide to LiPo Batteries, USA: Roger's Hobby Center.

[6] Albright, Greg, 2012, A comparative of Lead Acid to Lithium-Ion in Stationary Storage Applications, New York: AllCell Technologies LLC.

[7] Buchman, Isidor, 2011, BU-203: Nickelbased Batteries, Germany: Battery University. 